Check for updates

Cite this: RSC Adv., 2017, 7, 55496

Received 22nd October 2017

Accepted 22nd November 2017

DOI: $10.1039 / c 7 r a 11658 f$

rsc.li/rsc-advances

\section{Photoelectrocatalytic degradation of partially hydrolyzed polyacrylamide using a novel particle electrode}

\author{
Dejun Wang, (DD ${ }^{\text {ab }}$ Hui Li, ${ }^{c}$ Guangrui Wu, ${ }^{\text {ab }}$ Rui Guo, ${ }^{\text {ab }}$ Lin Li, $^{d}$ Chaocheng Zhao, (D) *ab \\ Fang Liu ${ }^{\mathrm{ab}}$ and Yongqiang Wang ${ }^{\mathrm{ab}}$
}

Tetrapyrazinoporphyrazines and their metal derivatives (TPyzPzs) are the most widely studied class of phthalocyanines azaanalogues. The present study describes a two-step synthesis for the cobalt complex of tetra-2,3-(5,6-di-tert-butyl-pyrazino) porphyrazine (tBu-TPyzPzCo) starting from pivalil, 2,3diaminomaleonitrile, metal salts, and urea. The product was ultrasonically impregnated onto carbon black (CB), wherein particle electrodes ( $t \mathrm{Bu}$-TpyzPzCo/CB) were employed for the degradation of partially hydrolyzed polyacrylamide (HPAM) in a three-dimensional electrocatalytic system under xenon lamp. HPAM exhibited more efficient degradation in the presence of a supporting catalyst using the photoelectrocatalytic process than by photocatalytic or electrocatalytic oxidation or even the sum of the two in saline water. The effects of HPAM degradation on various parameters in the photoelectrocatalytic reactor, such as the catalyst dosage, following the application of a cell voltage and an electrolyte were investigated in detail. Hydroxyl radicals and superoxide radicals were determined as the main active species in the reaction. The reaction mechanism was also discussed.

\section{Introduction}

Water-soluble anionic polyacrylamides have recently been widely employed to enhance oil recovery in the eastern oilfields of China. However, the presence of partially hydrolyzed polyacrylamide (HPAM) in production water generates certain problems, such as the increased difficulty of separating oil and water, and the natural degradation of HPAM, thereby producing toxic acrylamide and endangering the local ecosystem. ${ }^{\mathbf{1 , 2}}$ In recent years, research on HPAM degradation has focused on two aspects: chemical degradation ${ }^{3-7}$ and biodegradation. ${ }^{\mathbf{1 , 8 - 1 0}}$

Tetrapyrazinoporphyrazines and their metal derivatives (TPyzPzs) are the most widely studied class of phthalocyanine (Pc) azaanalogues ${ }^{\mathbf{1 1}}$ (Chart 1). The discovery of TPyzPzs has attracted significant attention because of their industrial applications in diverse areas, especially as materials for various electronic devices, ${ }^{12,13}$ photoactivators of singlet oxygen

${ }^{a}$ College of Chemical Engineering, China University of Petroleum (East China), No. 66, Changjiang West Road, Huangdao District, Qingdao, $P . R$ China. E-mail: zhaochch0821@163.com

${ }^{b}$ State Key Laboratory of Petroleum Pollution Control, China National Petroleum Corporation, 9 Dongzhimen North Street, Dongcheng District, Beijing, P. R. China

'Qingdao Technical College, No. 369, Qiantangjiang Road, Huangdao District, Qingdao, P. R China

${ }^{d}$ College of Chemical and Environmental Engineering, Shandong University of Science and Technology, No. 579, Qianwangang Road, Huangdao District, Qingdao, P. R China production for photodynamic therapy ${ }^{\mathbf{1 4 - 1 8}}$ and fluorescence quenchers for the detection of DNA. ${ }^{19-22}$

Three-dimensional electrodes are more attractive than twodimensional electrodes because of their extensive interfacial electrode surface and high mass transfer rates. ${ }^{23,24}$ In a threedimensional electrode system, many small regular or random particles are stacked in the electrical field and form charged microelectrodes, also called particle electrodes. ${ }^{25}$ In addition, particle electrode materials generally have continuous porosities, large specific surface areas, and high electrical conductivities, contributing to an increased mass transfer coefficient $^{26}$ as well as enhanced energy production. ${ }^{27}$ Literature indicates that the utilization of three-dimensional

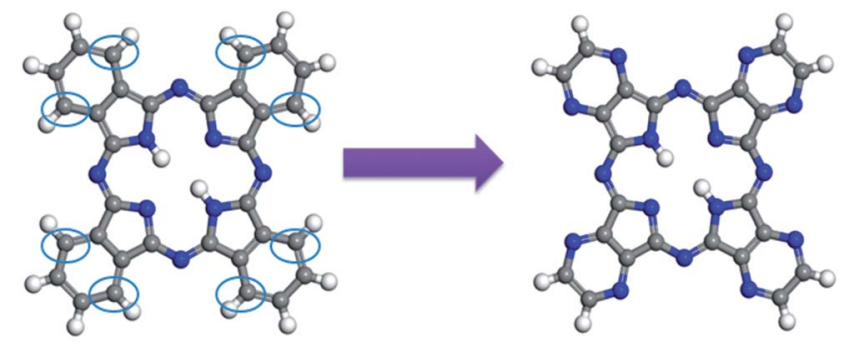

Phthalocyanine $(\mathrm{Pc})$

Tetrapyrazinoporphyrazine (TPyzPz)

Chart 1 Basic structures of phthalocyanine (PC) and tetrapyrazinoporphyrazine (TPyzPz). 


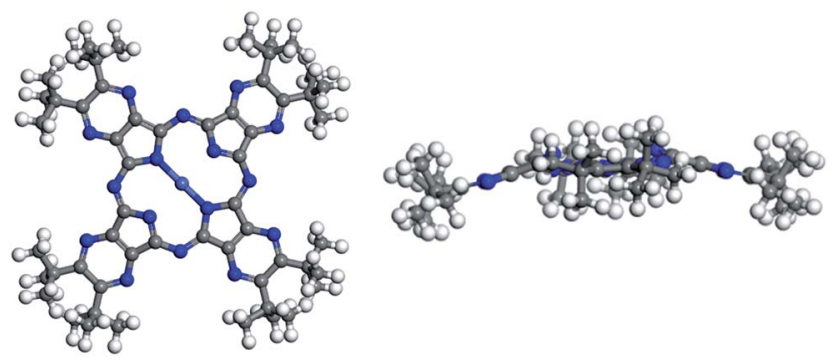

(a) Front view

(b) Side view

Chart 2 Structure of $t \mathrm{Bu}-\mathrm{TPy} z \mathrm{PzC}$.

electrodes can result in better wastewater treatment performance. ${ }^{28-32}$ However, the photoelectrocatalytic degradation of HPAM, which uses modified TPyzPzs as particle electrodes has not been reported.

In the following sections, the cobalt complex of tetra-2,3-(5,6di-tert-butyl-pyrazino) porphyrazine ( $t \mathrm{Bu}$-TPyzPzCo) (Chart 2$)$ is synthesized by a two-step method under nonspecific conditions with an emphasis primarily on the synthetic and structural aspects. $t \mathrm{Bu}-\mathrm{TPyzPzCo}$ is then loaded onto conductive carbon black to study its effect on HPAM removal efficiency in a photoelectrocatalytic system, of which we offer an explanation for the reaction mechanism.

\section{Experimental}

\section{Materials}

Carbon black (designated CB, $30 \mathrm{~nm}, 232 \mathrm{~m}^{2} \mathrm{~g}^{-1}$, Vulcan XC72R, Cabot Corporation, USA) was pretreated by ultrasonic cleaning in deionized water for $30 \mathrm{~min}$ at $30^{\circ} \mathrm{C}$. All of the other solvents, chemicals, and reagents were of AR grade, used as received, and purchased from the Sinopharm Chemical Reagent Company, China. The average molecular weight of HPAM is about $3 \times 10^{6}$ (the degree of hydrolysis of HPAM was about 16$18 \%)$.

\section{Characterization}

The UV-vis spectroscopy of the sample was recorded on a spectrophotometer (TU-1901, Pgeneral Instrument Inc., China), at a scan range of $300 \mathrm{~nm}$ to $800 \mathrm{~nm}$. X-ray diffraction (XRD) was performed on a PANalytical X'pert PRO X-ray diffractometer with $\mathrm{Cu} \mathrm{K} \alpha$ monochromatized radiation $(\lambda=$ $1.54 \AA$ ) operated at $45 \mathrm{kV}$ and $40 \mathrm{~mA}$. A scan rate of $8^{\circ} \mathrm{min}^{-1}$ and the $2 \theta$ scan range was from $0^{\circ}$ to $70^{\circ}$ was applied. The morphological information was collected on a scanning electron microscope (SEM) (Quanta200, FEI, Netherlands). The Fourier-transform infrared spectroscopy (FT-IR) spectrum was collected on a Nexus spectrometer (Magna FTIR750 , Nicolet, USA) within the range of $4000-400 \mathrm{~cm}^{-1}$ for 32 scans and the samples were prepared as $\mathrm{KBr}$ pellets. The cyclic voltammetry (CV) measurements were tested by a potentiostat (CHI660E, Chen Hua, China). The radicals were detected on an electron paramagnetic resonance (EPR) spectrometer (Elexsys 580, Bruker, Germany).

\section{Catalytic experiments}

The photoelectrocatalytic reaction was performed in a selfmade device, as presented by the schematic diagram in Fig. 1. In the device, an open rectangular sieve with a size of $16 \mathrm{~cm} \times$ $8 \mathrm{~cm} \times 15 \mathrm{~cm}$ was prepared as the main reactor with an effective volume of $1.92 \mathrm{~L}$, of which the photocatalytic reaction excitation light source was an air-cooled $300 \mathrm{~W}$ xenon lamp (PLS-SXE300, Perfect Light, China). The light source was placed above the main reactor. Titanium and 304 stainless steel were used as the anode and cathode materials, respectively. The electrode plate had a size of $12 \mathrm{~cm} \times 4 \mathrm{~cm}$, and the distance between the two plates was $5 \mathrm{~cm}$. The present study used a DC electrochemical unit power supply (MN605D, Zhaoxin, China) with a voltage range of $0-60 \mathrm{~V}$ and the current range of $0-5 \mathrm{~A}$. The reactor was placed on a magnetic stirrer, and a peristaltic pump was used to maintain the concentration of the reaction solution and the temperature during the reaction.

To study the possible enhancement effect of the photoelectrocatalytic process on the HPAM degradation experiments, we investigated the electrocatalytic, photocatalytic and photoelectrocatalytic processes under the same conditions. In each experiment, the HPAM solution at a certain concentration was set as the reaction solution, and sodium sulfate was added as the electrolyte. The reaction solution was magnetic-stirred for more than half an hour in the dark to eliminate the influence of the adsorption performance on the experimental results. While maintaining the other experimental conditions unchanged, the xenon lamp was turned on and the DC power supply was turned off at the same time when we investigated the photocatalytic properties, the electrocatalysis was opposite. Furthermore, when we investigated the photoelectrocatalytic properties, the xenon lamp and the DC power supply were turned on at the same time. The viscosity and concentration of the HPAM solution were sampled every $20 \mathrm{~min}$ and immediately measured during the reaction process. The concentration of HPAM was

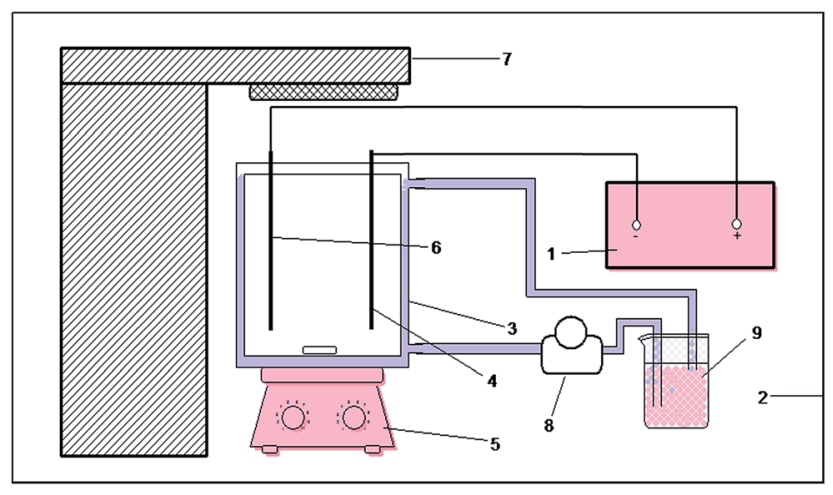

Fig. 1 Photoelectrocatalytic experimental device diagram. 1 DC; 2 darkroom; 3 main reactor; 4 stainless steel cathode; 5 magnetic stirrer; 6 titanium anode; 7 xenon lamp; 8 peristaltic pump; 9 circulating cooling water. 
measured by the starch-cadmium iodine method, ${ }^{33,34}$ using a UV-vis spectrophotometer. The viscosity of HPAM was measured by a numerical viscometer (DV-II+ Pro, Brookfield, USA). All the measurements were carried out at room temperature.

\section{Synthesis of $\boldsymbol{t B u}$-TPyzPzCo}

In a typical experiment, $t \mathrm{Bu}$-TPyzPzCo was synthesized by mixing pivalil (1) with 2,3-diaminomaleonitrile (2), urea (3), and cobalt chloride hydrate (4) in the presence of heat, of which a molar ratio of $1: 1: 4: 0.5$ from $1: 2: 3: 4$ obtained the best result. 1 was synthesized from pivaloin (5) by oxidation with chromic acid solution (6) based on the general procedure of Melvin S. Newman and A. Arkell. ${ }^{35}$

\section{Procedure for the preparation of $\boldsymbol{t B u - T P y z P z C o / C B}$}

There was $0.5 \mathrm{~g}$ of $t \mathrm{Bu}$-TPyzPzCo that was first dissolved in $80 \mathrm{~mL}$ DMF and ultrasonically dispersed for $0.5 \mathrm{~h}$. Then $1.5 \mathrm{~g}$ of carbon black was added and the sample continued to ultrasonic dispersion for $1 \mathrm{~h}$. The liquid was filtered and the residue was washed with DMF until the filtrate became colorless. The residue was washed with distilled water in triplicate and the residue was dried under a vacuum at $70{ }^{\circ} \mathrm{C}$ to produce $t \mathrm{Bu}-$ TPyzPzCo/CB.

\section{Results and discussions}

UV-visible spectrophotometry is an excellent method for phthalocyanine investigation and characterization. The spectra of phthalocyanine and its derivatives exhibit the characteristic $\mathrm{Q}$ and B bands. ${ }^{36-38}$ The UV-visible absorption spectra for $t \mathrm{Bu}-$ TPyzPzCo and unsubstituted TPyzPzCo are shown in Fig. 2, wherein DMF was employed as the solvent within the range of 300-800 nm. The compounds exhibited two evident absorption bands at $330 \mathrm{~nm}, 308 \mathrm{~nm}, 615.5 \mathrm{~nm}$ and $633.5 \mathrm{~nm}$, respectively, which correspond to the $\mathrm{B}$ and $\mathrm{Q}$ bands of the phthalocyanine azaanalogues. ${ }^{39,40}$ A comparison of the two spectra indicated the presence of $t \mathrm{Bu}$-TPyzPzCo absorption peaks, which are represented by a red shift in the UV region and a blue shift in the

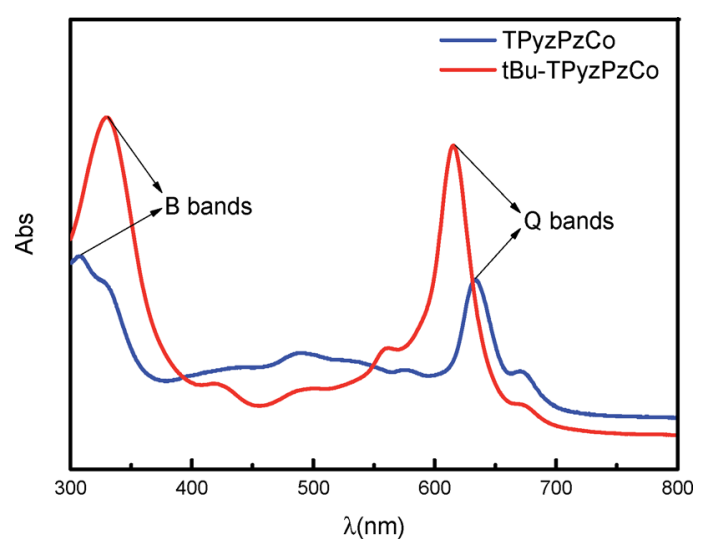

Fig. 2 UV-visible absorption spectra of unsubstituted TPyzPzCo (blue) and $t \mathrm{Bu}-\mathrm{TPyzPzCo}(\mathrm{red})$ in DMF solution. visible region, possibly due to the larger $\pi$ structure. In addition, several weak peaks near the $\mathrm{Q}$ band in the spectrum of the unsubstituted TpyzPzCo that were more intense than $t \mathrm{Bu}$ TpyzPzCo were observed. The peaks were attributed to the polymerization-produced dimer, ${ }^{\mathbf{4 1}}$ and affected the compounds' properties, thereby allowing the presence of peripheral substituents to suppress dimer generation.

The structural features of the compound were checked by the XRD measurements in Fig. 3, wherein very obvious characteristic metal phthalocyanine complex diffraction peaks were observed in the range of $2 \theta=10-30^{\circ}$ (ref. 42$)\left(2 \theta=12.95^{\circ}\right.$, $14.88^{\circ}, 15.49^{\circ}, 17.77^{\circ}, 19.73^{\circ}, 21.52^{\circ}, 27.45^{\circ}$, and $\left.28.82^{\circ}\right)$. After loading, the characteristic diffraction peaks of the metal phthalocyanine complex were still detected on the XRD patterns, thereby indicating the presence of $t \mathrm{Bu}-\mathrm{TPy} P \mathrm{PzC}$ in the form of crystals in the complex.

The FT-IR spectra of $t$ Bu-TPyzPzCo before and after loading are presented in Fig. 4, and they were recorded for the fundamental region of $400-4000 \mathrm{~cm}^{-1}$ and used the $\mathrm{KBr}$ disk technique. The two spectra exhibited particularly similar absorption peaks around 769, 964, 1122 and $1329 \mathrm{~cm}^{-1}$, which may present the phthalocyanine skeletal vibrations. ${ }^{43}$ Due to the presence of the tert-butyls, the spectra also exhibited absorption peaks in the range around $1375 \mathrm{~cm}^{-1}$. Specifically, two peaks was observed at $1371 \mathrm{~cm}^{-1}$ and $1386 \mathrm{~cm}^{-1}$, wherein the strength of the former was about two-fold that of the latter. In addition, two absorption peaks were observed around $1456 \mathrm{~cm}^{-1}$ and $1682 \mathrm{~cm}^{-1}$, which represents the $\mathrm{C}=\mathrm{C}$ and $\mathrm{C}=\mathrm{N}$ bonds stretching vibration of the pyrazine macrocycles.

Fig. 5 displays the morphology of $t \mathrm{Bu}$-TPyzPzCo before and after loading, and the energy dispersive X-ray analysis (EDAX) of $t \mathrm{Bu}-\mathrm{TPyzPzCo} / \mathrm{CB}$. The SEM image exhibited the random pore size distributions and interconnected pore systems in the compound, wherein a sheet structure with a thickness of about 1 $\mu \mathrm{m}$ is observed. After loading, the loose holes in the carbon black were covered to some extent by the catalyst. In addition, the catalyst was well-loaded on the conductive carrier, and the presence of the cobalt element on the EDAX spectrum was observed.

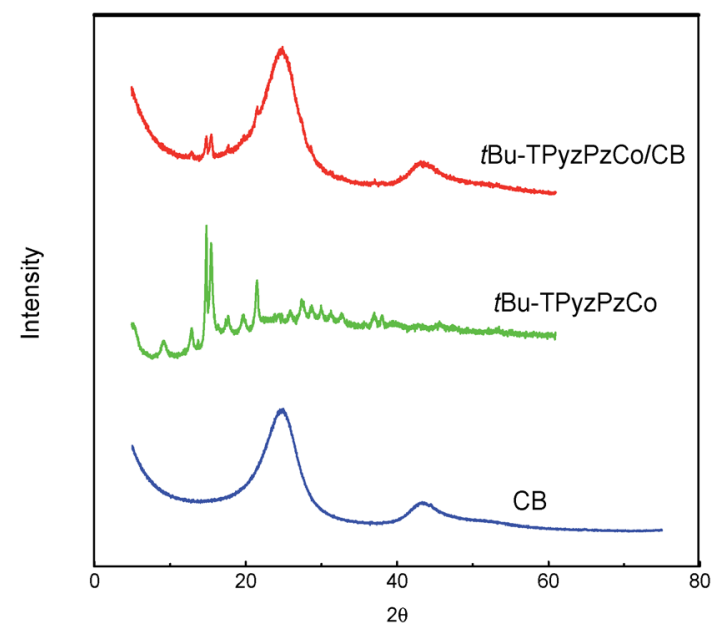

Fig. 3 Powder XRD patterns of $t \mathrm{Bu}$-TPyzPzCo before and after loading. 


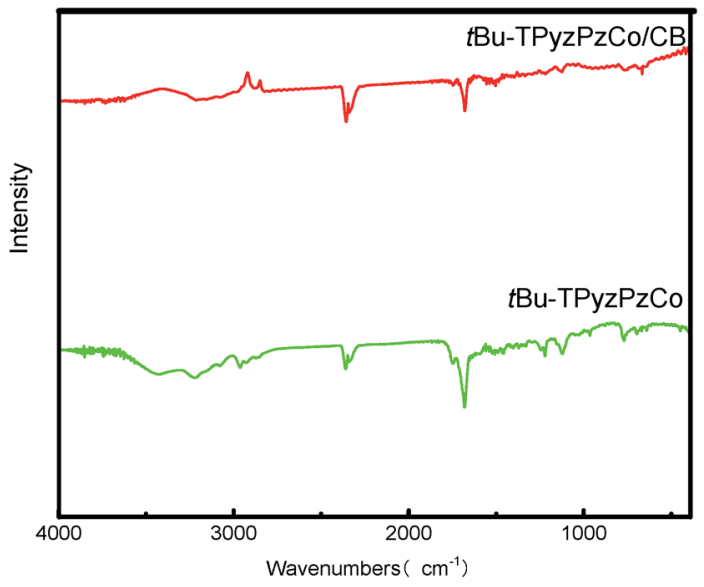

Fig. 4 FT-IR spectroscopy results of $t \mathrm{Bu}-\mathrm{TPyzPzC}$ before and after loading.

The catalytic performance results of $t \mathrm{Bu}-\mathrm{TPyzPzCo}$ and $t \mathrm{Bu}-$ TPyzPzCo/CB in the different processes are presented in Fig. 6, wherein the HPAM removal efficiency and viscosity of the unsupported catalyst were significantly lower than the supported catalyst for each catalytic process. For $t \mathrm{Bu}-\mathrm{TPyzPzCo} / \mathrm{CB}$, the efficiency of degradation of HPAM in percentage was less than $50 \%$ following the $2 \mathrm{~h}$ degradation of the single catalytic process. In contrary, the photoelectrocatalysis exhibited a percentage of $94.55 \%$ and was much higher than the sum of the two. This fact indicated the presence of a synergistic enhancement effect in the combined process as well as the presence of several influence factors on the viscosity of polymer, such as temperature, concentration and molecular weight. In the present study, the $50 \mathrm{mg} \mathrm{L}^{-1}$ HPAM solution exhibited an initial viscosity of $8.33 \mathrm{mPa}$. The viscosity was reduced to 5.62 $\mathrm{mPa} \mathrm{s}$ following the addition of the $\mathrm{Na}_{2} \mathrm{SO}_{4}$ electrolyte and catalyst after half an hour of magnetic stirring because the viscosity of the solution was susceptible to the influence of the anion and the stirring. With the progress of the reaction, HPAM exhibited gradual degradation and the viscosity of the solution

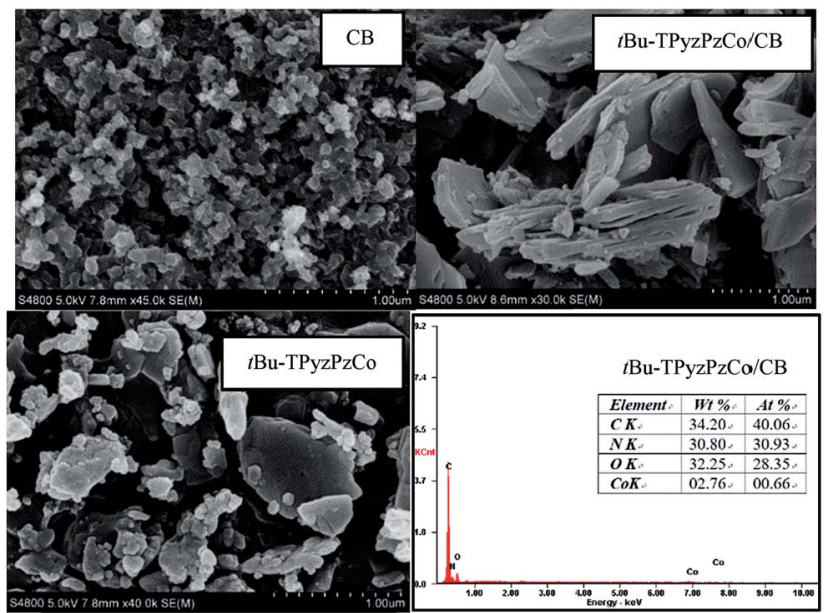

Fig. 5 SEM images of $t \mathrm{Bu}$-TPyzPzCo before and after loading and the EDAX of the supported catalyst.
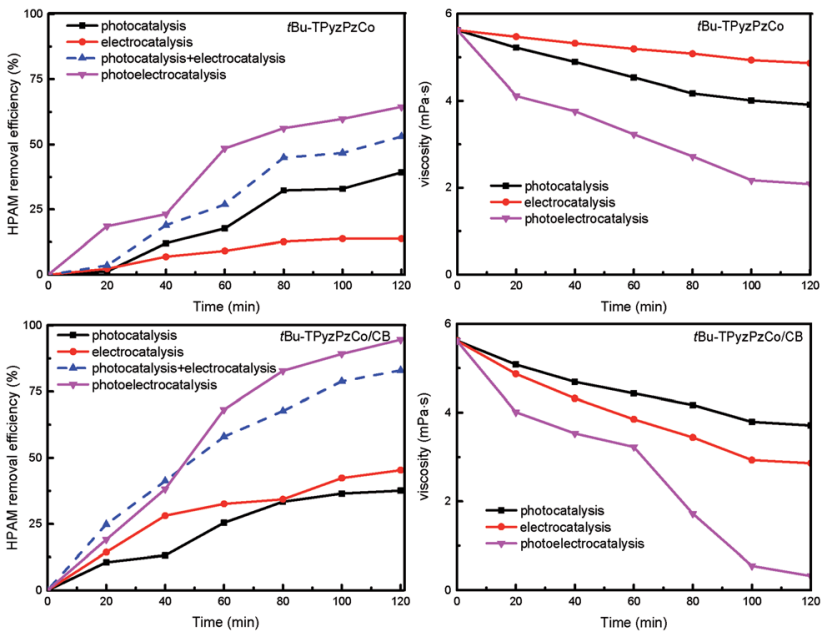

Fig. 6 Comparison of degradation of HPAM by the different catalytic processes $\left(M_{\text {electrolyte }}=0.1 \mathrm{~mol} \mathrm{~L}^{-1}, c_{0}=50 \mathrm{mg} \mathrm{L}^{-1}, U=40 \mathrm{~V}, M_{\text {catalyst }}\right.$ $=0.3 \mathrm{~g} \mathrm{~L}^{-1}$ ).

correspondingly decreased, of which the downward trend was consistent with the degradation efficiency.

The dose of catalyst is an important influence factor when characterizing the degradation of an organic contaminant. The effect of the $t \mathrm{Bu}-\mathrm{TPyzPzCo} / \mathrm{CB}$ dosage on the photoelectrocatalytic performance is presented in Fig. 7, wherein the addition of the catalyst contributed to the degradation of HPAM regardless of the dosage. Among the different catalyst dosages, the $0.3 \mathrm{~g} \mathrm{~L}^{-1}$ catalyst exhibited the highest degradation rate, while doses lower or higher than $0.3 \mathrm{~g} \mathrm{~L}^{-1}$ impacted the results. The small catalyst amount resulted in the involvement of less active components. However, HPAM exhibited flocculation as the catalyst agglomerated, which hindered the normal mass transfer process. Meanwhile, the catalyst was used excessively due to the presence of a shielding effect that was caused by light scattering and carbon black absorbance, thus hindering the penetration of light. ${ }^{44}$ In this experiment, the degradation rate of the HPAM solution was only $15.7 \%$ when using the catalyst with a dosage of $0.1 \mathrm{~g} \mathrm{~L}^{-1}$. In addition, the rate did not increase following the addition of a catalyst that had a dose of more than

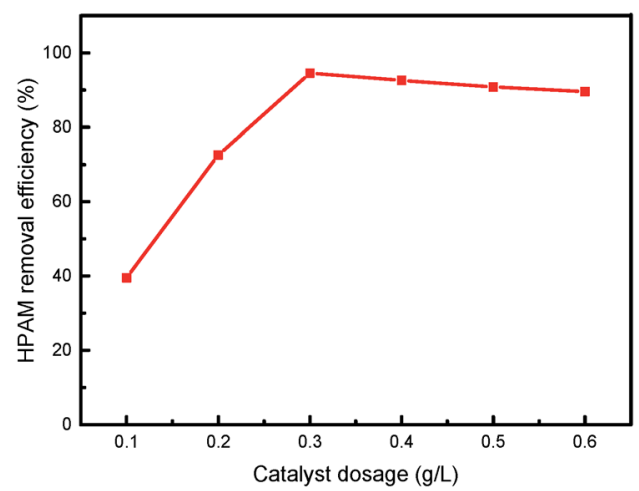

Fig. 7 Effect of dose on the degradation of HPAM by photoelectrocatalysis ( $M_{\text {electrolyte }}=0.1 \mathrm{~mol} \mathrm{~L}^{-1}, c_{0}=50 \mathrm{mg} \mathrm{L}^{-1}, U=40 \mathrm{~V}$ ). 


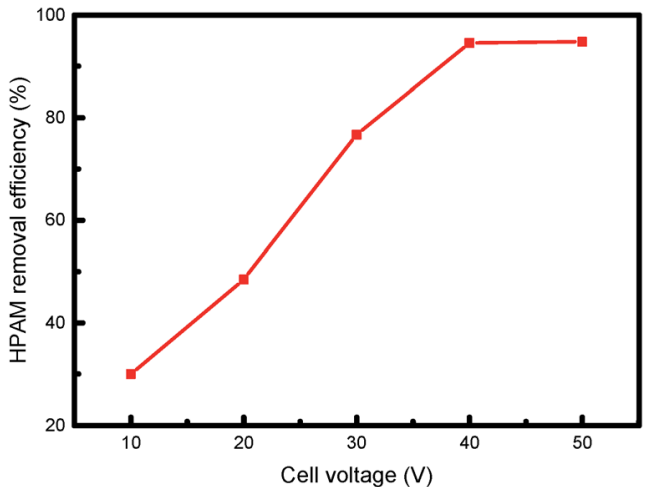

Fig. 8 Effect of cell voltage on degradation of HPAM by photoelectrocatalysis $\left(M_{\text {electrolyte }}=0.1 \mathrm{~mol} \mathrm{~L}^{-1}, c_{0}=50 \mathrm{mg} \mathrm{L}^{-1}, M_{\text {catalyst }}=\right.$ $\left.0.3 \mathrm{~g} \mathrm{~L}^{-1}\right)$.

$0.3 \mathrm{~g} \mathrm{~L}^{-1}$, of which the solution remained at around $90 \%$. The HPAM solution exhibited the best removal efficiency for a dosage of $0.3 \mathrm{~g} \mathrm{~L}^{-1}$, and exhibited a degradation rate of $94.55 \%$. Thus, the dosage of the catalyst is an important factor that affects the photoelectrocatalytic performance.

Cell voltage plays an important role in the photoelectrocatalytic degradation of organic pollutants, and has a variety of versatile effects on photocatalytic reactions: not only can it enhance the degradation rate of organic pollutants, but it can also change the degradation mechanism. ${ }^{45}$ The present research investigated the impact of voltage on the HPAM degradation rate by changing the cell voltage applied between the anode and cathode, the results of which are presented in Fig. 8. When the voltage was lower than $40 \mathrm{~V}$, the electrocatalytic efficiency increased following an increase in the voltage. On the other hand, voltages higher than $40 \mathrm{~V}$ exhibited insignificant HPAM removal rates increase. Moreover, a high cell voltage was resulted in high-energy consumption and low efficiency. As a result, we chose $40 \mathrm{~V}$ in our follow-up work. In practical industrial applications, low-economic costs and high-efficiency must be considered when selecting the appropriate cell voltage.

To investigate the effect of the electrolyte species on the degradation of HPAM by the photoelectrocatalytic process, we

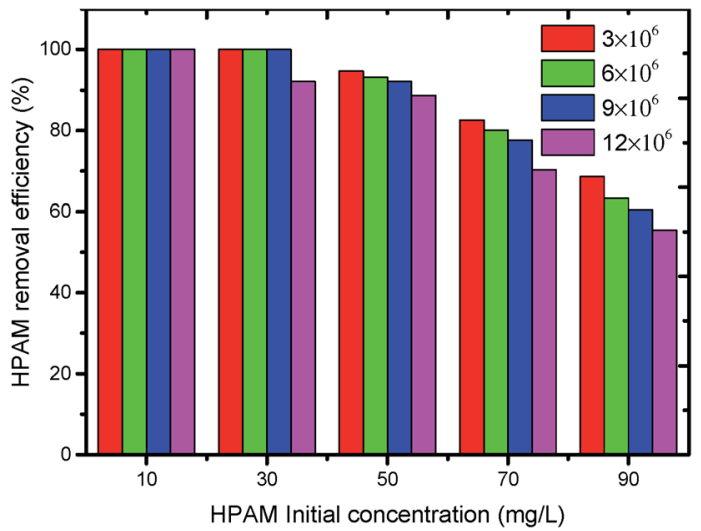

Fig. 10 Effect of initial concentration and relative molecular mass of HPAM on degradation of HPAM by photoelectrocatalysis (Melectrolyte $=$ $0.1 \mathrm{~mol} \mathrm{~L}^{-1}, M_{\text {catalyst }}=0.3 \mathrm{~g} \mathrm{~L}^{-1}$ ).

added $0.05 \mathrm{~mol} \mathrm{~L}^{-1}$ sodium sulfate and sodium chloride as the electrolyte, respectively, of which the removal efficiency of HPAM is shown in Fig. 9. The electrical conductivity of $\mathrm{Na}_{2} \mathrm{SO}_{4}$ was higher than that of $\mathrm{NaCl}$ at the same molarity. However, in the photoelectrocatalytic process system, the difference in the HPAM removal efficiency between the two was very small given that $\mathrm{Cl}_{2}$ was produced on the anode surface in the presence of $\mathrm{Cl}^{-}$in the solution, and then hydrolyzed to produce hypochlorous acid, ${ }^{\mathbf{4 6}-\mathbf{4 8}}$ thereby generating a strong oxidizing effect on HPAM. In addition, the degradation was significantly promoted following the addition of $\mathrm{NaCl}$ to the $\mathrm{Na}_{2} \mathrm{SO}_{4}$ solution, thereby indicating that the presence of $\mathrm{Cl}^{-}$produced a synergistic effect on the combined process.

The effect of initial concentration and relative molecular mass of HPAM on degradation of HPAM by photoelectrocatalysis is shown in Fig. 10. The result shows that the removal efficiency decreases with the initial concentration and relative molecular mass of HPAM increasing. Therefore, our study has only been exploratory, so there are still some limitations in the treatment of oilfield wastewater containing high molecular weight HPAM. Later we will try to make nanocatalyst and add pretreatment to reduce the molecular weight.

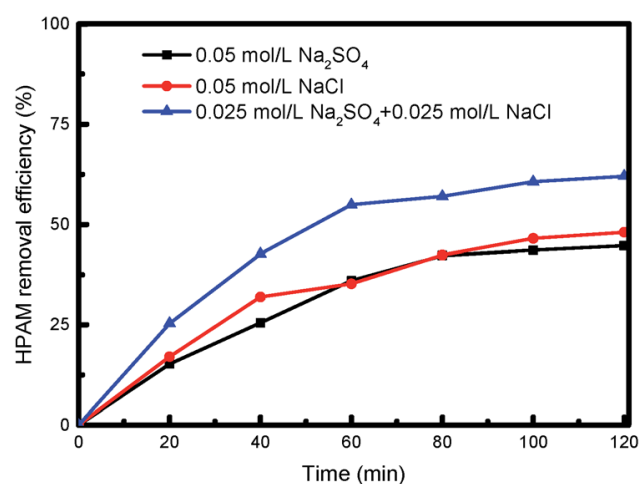

Fig. 9 Effect of electrolyte on degradation of HPAM by photoelectrocatalysis $\left(c_{0}=50 \mathrm{mg} \mathrm{L}^{-1}, U=40 \mathrm{~V}, M_{\text {catalyst }}=0.3 \mathrm{~g} \mathrm{~L}^{-1}\right)$.

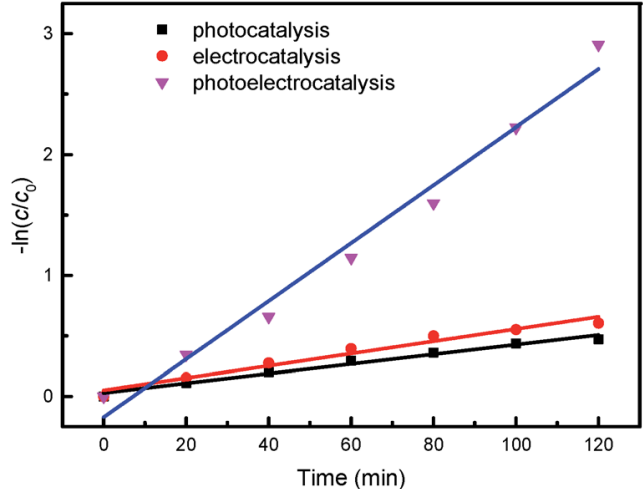

Fig. 11 Kinetic analysis of the three catalytic processes ( $M_{\text {electrolyte }}=$ $0.1 \mathrm{~mol} \mathrm{~L}^{-1}, c_{0}=50 \mathrm{mg} \mathrm{L}^{-1}, U=40 \mathrm{~V}, M_{\text {catalyst }}=0.3 \mathrm{~g} \mathrm{~L}^{-1}$ ). 
Table 1 Kinetics reaction rate constants of the three catalytic processes

\begin{tabular}{llllll}
\hline No. & Cell voltage $(\mathrm{V})$ & $\mathrm{Na}_{2} \mathrm{SO}_{4}\left(\mathrm{~mol} \mathrm{~L}^{-1}\right)$ & Reaction rate $\left(\mathrm{min}^{-1}\right)$ & $R^{2}$ & Process \\
\hline 1 & - & 0.1 & $3.98 \times 10^{-3}$ & 0.9789 & Photocatalytic \\
2 & 40 & 0.1 & $5.05 \times 10^{-3}$ & 0.9614 & Electrocatalytic \\
3 & 40 & 0.1 & $2.4 \times 10^{-2}$ & 0.9771 & Photoelectrocatalytic
\end{tabular}

The Langmuir-Hinshelwood reaction formula was employed to linearly fit the results of the three catalytic processes, as presented in Fig. 11.

The results confirmed that all three of the HPAM catalytic degradation processes were quasi-first order reaction. The photoelectrocatalytic system exhibited a reaction rate constant of $2.4 \times 10^{-2} \mathrm{~min}^{-1}$, which was 6.03 fold that of photocatalysis and 3.97 fold that of the electrocatalytic reaction. The reaction rate constants and the fitting correlation coefficients of the three catalytic processes are shown in Table 1.

To investigate the electrochemical properties of $t \mathrm{Bu}-$ TPyzPzCo/CB, a set of cyclic voltammetry measurements were performed in a standard three-electrode assembly, that consisted of a $t \mathrm{Bu}$-TPyzPzCo/CB electrode as the anode (working electrode), a Pt wire as the cathode (counter electrode), and an SCE electrode. The test solution, which was composed of $0.1 \mathrm{~mol} \mathrm{~L}^{-1} \mathrm{Na}_{2} \mathrm{SO}_{4}$ and $50 \mathrm{mg} \mathrm{L}^{-1} \mathrm{HPAM}$, was heated until it was bubbling with high purity nitrogen for $30 \mathrm{~min}$ to remove the dissolved oxygen from the electrolyte. In the tests, the linear sweep voltammetry was recorded at a scanning step of $100 \mathrm{mV}$ $\mathrm{s}^{-1}$, of which the results of the cyclic voltammetry are shown in Fig. 12. The electrocatalytic degradation of HPAM was determined to be an oxidation-reduction reaction. The oxidation potential $E_{\mathrm{pa}}$ was determined to be $1.266 \mathrm{~V}$ and the reduction potential $E_{\mathrm{pc}}$ was $-1.246 \mathrm{~V}$. In addition, an oxidation current $I_{\mathrm{pa}}$ of $-1.571 \mathrm{~mA}$ and reduction current $I_{\mathrm{pc}}$ of $1.059 \mathrm{~mA}$ versus SCE was observed for the $t \mathrm{Bu}-\mathrm{TPy} \mathrm{PzCo} / \mathrm{CB}$ electrode, respectively. Therefore, we concluded that the degradation reaction was quasi-reversible.

To further establish the photoelectrocatalytic degradation mechanism of HPAM in the reactor, we recorded the EPR

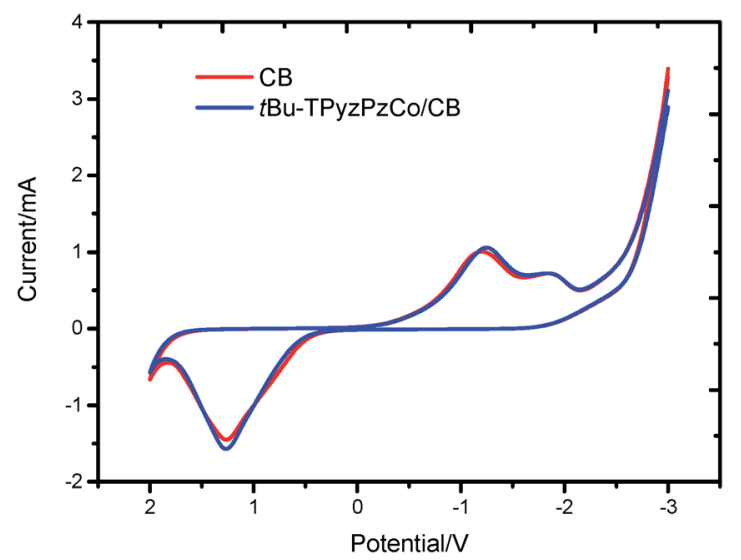

Fig. 12 Cyclic voltammetry curve of the $t \mathrm{Bu}$-TPyzPzCo/CB electrode. spectrum of the 5,5-dimethyl-1-pyrroline $N$-oxide (DMPO) spin trap adduct, as presented in Fig. 13. An EPR spectrum displaying signals with a characteristic intensity ratio of $1: 2: 2: 1$ for the DMPO-OH adducts in the pure water system and six characteristic peaks for the DMPO-OOH/DMPO- ${ }_{2}{ }^{-}$ adducts in the methanol system were obtained, wherein the results validate the formation of the hydroxyl radicals and superoxide radicals in the photoelectrocatalytic reactor. Thus, the present study concluded the involvement of the photoelectrocatalytic degradation mechanisms of HPAM over the immobilized $t \mathrm{Bu}$-TPyzPzCo in its generation and reaction with the hydroxyl radicals and superoxide radicals in the processes.

Studies have shown that the mechanism for photocatalytic oxidation of pollutants in the three-dimensional electrode system include direct oxidation and indirect oxidation. The former includes the direct electron transfer on the anode and photocatalyst surface, and the latter includes electro-generated and photo-generated oxidizing species, e.g., ${ }^{\circ} \mathrm{OH}$ and $\mathrm{O}_{2}{ }^{\cdot-}$. The main pathways to generate free radicals in our research were as follows: $(\mathrm{P}=$ catalyst $)$

$$
\begin{gathered}
\mathrm{H}_{2} \mathrm{O} \stackrel{\text { electrolysis }}{\longrightarrow} \cdot \mathrm{OH}+\mathrm{H}^{+}+\mathrm{e}^{-} \\
\mathrm{P} \stackrel{h v}{\longrightarrow} \mathrm{P}^{*}+\mathrm{H}_{2} \mathrm{O} \rightarrow \mathrm{P}^{\cdot-}+\cdot \mathrm{OH}+\mathrm{H}^{+}+\mathrm{e}^{-} \\
\mathrm{P} \stackrel{h v}{\longrightarrow} \mathrm{P}^{*} \stackrel{\text { ISO }}{\longrightarrow} \mathrm{P}^{*}+\mathrm{H}_{2} \mathrm{O} \rightarrow \mathrm{P}^{\cdot-}+\cdot \mathrm{OH}+\mathrm{H}^{+}+\mathrm{e}^{-} \\
\mathrm{O}_{2}+\mathrm{e}^{-} \rightarrow \mathrm{O}_{2}^{\cdot-} \\
\mathrm{P}^{\cdot-}+\mathrm{O}_{2} \rightarrow \mathrm{P}^{\cdot}+\mathrm{O}_{2}{ }^{--}
\end{gathered}
$$

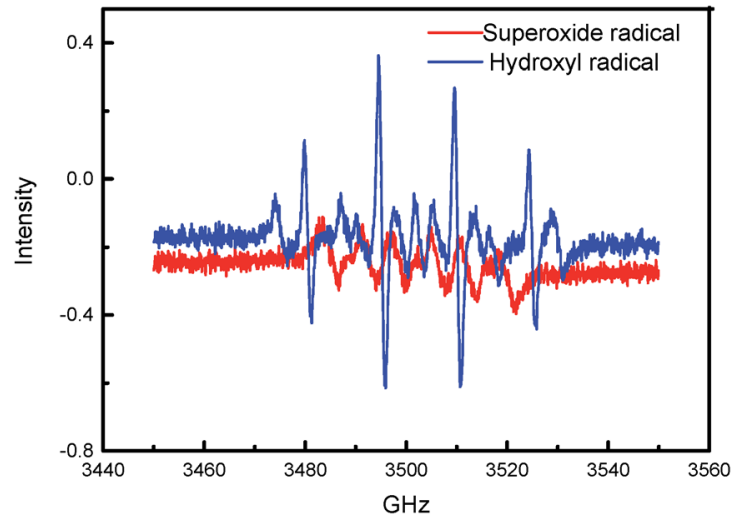

Fig. 13 EPR detection spectra of the radicals in the photoelectrocatalytic process. 


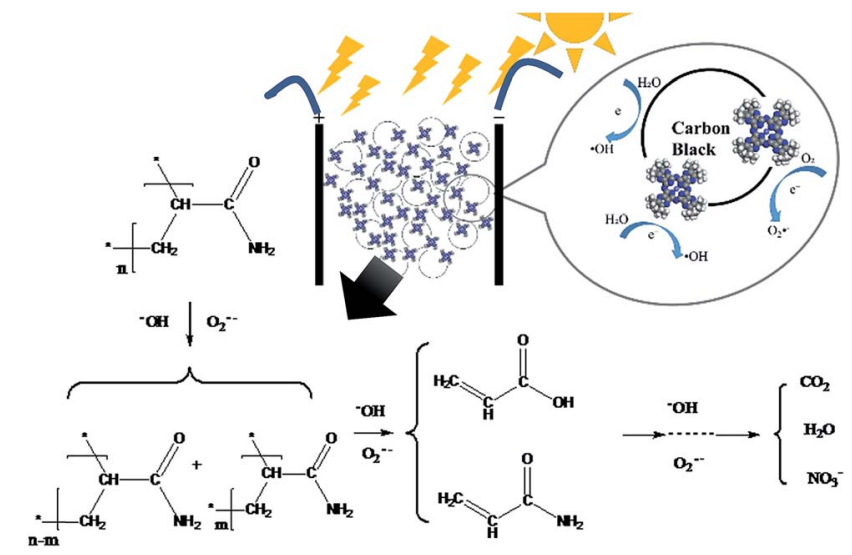

Fig. 14 Degradation mechanism of HPAM by photoelectrocatalysis using $t \mathrm{Bu}-\mathrm{TPy} \mathrm{Pz} \mathrm{Co} / \mathrm{CB}$ particle electrodes.

According to the possible degradation pathways, the chain scission reaction first occurs and breaks HPAM into various units with relatively small molecular weight., ${ }^{1,3,8}$ According to our research, the small molecules were then degraded over $t \mathrm{Bu}$ TPyzPzCo/CB under xenon lamp irradiation and an external electric field. To clearly investigate the degradation pathway, we used a multi-instrument joint method to detect the intermediates, specifically PyGCMS, ${ }^{1} \mathrm{HNMR}$, HSGCMS, and EDX. Notably, we did not use HPLC/MS because the high concentration of the electrolyte generated seriously distorted results. The results characterized acrylamide monomer and acrylic acid as the intermediates. Based on these observations, a possible pathway for the photoelectrocatalytic degradation of HPAM is proposed in Fig. 14.

\section{Conclusions}

In summary, a $t \mathrm{Bu}-\mathrm{TPy} \mathrm{PzCo} / \mathrm{CB}$ composite catalyst was prepared by the ultrasonic impregnation method. Following the degradation of HPAM over the catalyst in a photoelectrocatalytic process, significant decrease was observed in the concentration and viscosity of the HPAM solution, which illustrates the excellent photoelectrocatalytic activity of the as-prepared catalysts. Based on the research results of the photoelectrocatalytic process, although the two signal catalytic processes were simply combined, a significantly synergistic enhancement effect was also generated apart from the degradation effects observed in the two respective processes. The presented photoelectric combination operation mode has many advantages, such as the simple combination of several processes and the rapid treatment of refractory wastewater, and exhibits practical value for the improvement of existing facilities.

\section{Conflicts of interest}

There are no conflicts to declare.

\section{Acknowledgements}

The authors would like to acknowledge the financial support they received from the National Science and Technology Major
Project of the Ministry of Science and Technology of China (Grant No. 2016ZX05040003). We also gratefully acknowledge the Research Department of the China University of Petroleum (East China) for supporting this work.

\section{Notes and references}

1 M. Bao, Q. Chen, Y. Li and G. Jiang, J. Hazard. Mater., 2010, 184, 105-110.

2 F. Ma, L. Wei, L. Wang and C.-C. Chang, Int. J. Biotechnol, 2008, 10, 55-63.

3 X. Rong, F. Qiu, C. Zhang, L. Fu, Y. Wang and D. Yang, J. Alloys Compd., 2015, 639, 153-161.

4 H. Zhang, Z. Zhong and W. Xing, Desalination, 2013, 309, 84-90.

5 Z.-z. Lu and Y.-h. She, J. Yangtze Univ., Nat. Sci. Ed., Sci. Eng., 2008, 1, 056.

6 T. Liu, H. You and Q. Chen, J. Hazard. Mater., 2009, 162, 860865.

7 S. Vijayalakshmi and G. Madras, J. Appl. Polym. Sci., 2006, 100, 3997-4003.

8 Q. Wen, Z. Chen, Y. Zhao, H. Zhang and Y. Feng, J. Hazard. Mater., 2010, 175, 955-959.

9 Z. Y. W. N. L. Fengkai and G. Yi, Environ. Prot. Oil Gas Fields, 2005, 4, 014.

10 Q. Wen, Z. Chen, Y. Zhao, H. Zhang and Y. Feng, J. Polym. Environ., 2011, 19, 125-132.

11 M. P. Donzello, C. Ercolani, V. Novakova, P. Zimcik and P. A. Stuzhin, Coord. Chem. Rev., 2016, 309, 107-179.

12 V. Novakova, L. Lochman, I. Zajícová, K. Kopecky, M. Miletin, K. Lang, K. Kirakci and P. Zimcik, Chem.-Eur. J., 2013, 19, 5025-5028.

13 L. Lochman, P. Zimcik, I. Klimant, V. Novakova and S. M. Borisov, Sens. Actuators, B, 2017, 246, 1100-1107.

14 M. Kostka, P. Zimcik, M. Miletin, P. Klemera, K. Kopecky and Z. Musil, J. Photochem. Photobiol., A, 2006, 178, 16-25.

15 P. Zimcik, M. Miletin, M. Kostka, J. Schwarz, Z. Musil and K. Kopecky, J. Photochem. Photobiol., A, 2004, 163, 21-28.

16 S. Makhseed, A. Tuhl, J. Samuel, P. Zimcik, N. Al-Awadi and V. Novakova, Dyes Pigm., 2012, 95, 351-357.

17 V. Novakova, P. Zimcik, K. Kopecky, M. Miletin, J. Kuneš and K. Lang, Eur. J. Org. Chem., 2008, 2008, 3260-3263.

18 Z. Musil, P. Zimcik, M. Miletin, K. Kopecky, M. Link, P. Petrik and J. Schwarz, J. Porphyrins Phthalocyanines, 2006, 10, 122-131.

19 G. K. Kantar, Ö. Faiz, O. Şahin and S. Şaşmaz, J. Chem. Sci., 2017, 129, 1247-1256.

20 K. Kopecky, V. Novakova, M. Miletin, R. Kučera and P. Zimcik, Bioconjugate Chem., 2010, 21, 1872-1879.

21 K. Kopecky, D. Šatinský, V. Novakova, M. Miletin, A. Svoboda and P. Zimcik, Dyes Pigm., 2011, 91, 112-119.

22 K. Kopecky, V. Novakova, M. Miletin, R. Kučera and P. Zimcik, Tetrahedron, 2011, 67, 5956-5963.

23 X. Wu, X. Yang, D. Wu and R. Fu, Chem. Eng. J., 2008, 138, 47-54.

24 D. Pletcher and F. C. Walsh, Electrochemical Technology for a Cleaner Environment, The Electrosynthesis Company Inc., Lancaster, New York, 1992. 
25 W. Kong, B. Wang, H. Ma and L. Gu, J. Hazard. Mater., 2006, 137, 1532-1537.

26 L. Wei, S. Guo, G. Yan, C. Chen and X. Jiang, Electrochim. Acta, 2010, 55, 8615-8620.

27 H. Wang, M. Davidson, Y. Zuo and Z. Ren, J. Power Sources, 2011, 196, 5863-5866.

28 Z. He, Environ. Sci. Technol., 2013, 47, 332-333.

29 Y. Mu, K. Rabaey, R. A. Rozendal, Z. Yuan and J. Keller, Environ. Sci. Technol., 2009, 43, 5137-5143.

30 A. Polcaro, S. Palmas, F. Renoldi and M. Mascia, Electrochim. Acta, 2000, 46, 389-394.

31 B. Wang, W. Kong and H. Ma, J. Hazard. Mater., 2007, 146, 295-301.

32 Y. Xiong, P. J. Strunk, H. Xia, X. Zhu and H. T. Karlsson, Water Res., 2001, 35, 4226-4230.

33 J. Lu and L. Wu, J. Agric. Food Chem., 2002, 50, 5038.

34 M. W. Scoggins and J. W. Miller, Anal. Chem., 1975, 47, 152154.

35 M. S. Newman and A. Arkell, J. Org. Chem., 1959, 24, 385-387. 36 H. Xia and M. Nogami, Opt. Mater., 2000, 15, 93-98.

37 A. Hadasch, A. Sorokin, A. Rabion and B. Meunier, New J. Chem., 1998, 22, 45-51.
38 W. Chen, B. Zhao, Y. Pan, Y. Yao, S. Lu, S. Chen and L. Du, J. Colloid Interface Sci., 2006, 300, 626.

39 K. Kopecky, P. Zimcik, V. Novakova, M. Miletin, Z. Musil and J. Stribna, Dyes Pigm., 2008, 78, 231-238.

40 S. Makhseed, J. Samuel and F. Ibrahim, Tetrahedron, 2008, 64, 8871-8877.

41 J. Liu, Y. Zhao, F. Zhang, F. Zhao, Y. Tang, X. Song and G. Yao, Acta Phys.-Chim. Sin., 1996, 12, 163-167.

42 Y. Suo, The Syntheses and Application of Phthalocyanines, Chemical Industry Press, Beijing, 2000.

43 A. N. Sidorov and I. P. Kotlyar, Opt. Spectrosc., 1961, 11, 92.

44 L. Wu, A. Li, G. Gao, Z. Fei, S. Xu and Q. Zhang, J. Mol. Catal. A: Chem., 2007, 269, 183-189.

45 K. Vinodgopal, U. Stafford, K. A. Gray and P. V. Kamat, J. Phys. Chem., 1994, 98, 6797-6803.

46 C. Comninellis and A. Nerini, J. Appl. Electrochem., 1995, 25, 23-28.

47 M. J. Watts and K. G. Linden, Water Res., 2007, 41, 2871.

48 K. H. Wang, Y. H. Hsieh, C. H. Wu and C. Y. Chang, Chemosphere, 2000, 40, 389-394. 